\title{
Analysis of Dynamic Damage Fractal and Energy Consumption Characteristics of Dolomite Marble
}

\author{
Ting Zuo $\mathbb{D}^{1}{ }^{1}$ Zehu Zhao, ${ }^{1}$ Jianguo Wang $\mathbb{D}^{1,2}$ Xianglong Li ${ }^{1},{ }^{1,2}$ Zihao Tao ${ }^{1}{ }^{1}$ \\ and Changhui Yang ${ }^{1}$ \\ ${ }^{1}$ Faculty of Land Resources Engineering, Kunming University of Science and Technology, Kunming, Yunnan 650093, China \\ ${ }^{2}$ Yunnan Key Laboratory of Sino-German Blue Mining and Utilization of Special Underground Space, \\ Kunming University of Science and Technology, Kunming, Yunnan 650093, China
}

Correspondence should be addressed to Jianguo Wang; wangjg0831@163.com and Xianglong Li; 1xl00014002@163.com

Received 23 September 2021; Revised 18 December 2021; Accepted 3 January 2022; Published 28 January 2022

Academic Editor: Bin Gong

Copyright (c) 2022 Ting Zuo et al. This is an open access article distributed under the Creative Commons Attribution License, which permits unrestricted use, distribution, and reproduction in any medium, provided the original work is properly cited.

To investigate the damage fractal and energy dissipation of dolomite marble under blasting load, Dahongshan Copper Mine was selected as the test object and one-dimensional SHPB impact tests with different strain rates were carried out. The dynamic compressive strength, damage morphology, fractal fragmentation, and energy dissipation of the rock were analyzed. The results showed that the absorbed energy per unit volume and the crushing energy per unit mass of dolomite marble are closely related to the dynamic compressive strength. The fractal dimension $D$ of dolomite marble increases with increasing strain rate, and the smaller the average block size of the rock, the degree of crushing deepens. In addition, as the incident energy increases, the crushing energy of the rock also increases, and the energy dissipation intensifies. Finally, after comparative analysis, the reasonable strain rate range is $68.14-77.61 \mathrm{~s}^{-1}$, and the reasonable specific energy absorption value range is $0.65-0.98 \mathrm{~J} / \mathrm{cm}^{3}$. The fractal pattern of rock deformation and damage can be reasonably explained from the perspective of energy dissipation.

\section{Introduction}

Blasting has been an indispensable technology in current mining methods [1-3]. Therefore, it is vital to study the impact of blasting stress waves on the surrounding rock mass as well as the process of rock damage and the mechanism of fragmentation. Dynamic mechanical characteristics and energy consumption regularities of rocks are involved in various engineering fields and natural disasters, such as roadway excavation, hydraulic engineering excavation, underground mine mining, earthquakes, and landslides. This geological engineering has enabled the vigorous development of rock dynamics and related disciplines, and has gradually attracted the attention of the field of rock and soil mechanics [4]. When using mechanical equipment to break the rock or blasting technology for excavation, the strain rate of rock is basically $10^{1}-10^{3} \mathrm{~s}^{-1}$; therefore, the split Hopkinson pressure bar (SHPB) test is used to study the dynamic mechanical characteristics of rock $[5,6]$.
So far, there have been many valuable research results on the dynamic mechanical characteristics and energy dissipation regularities of rocks [7]. For example, Ding et al. [8] combined fractal theory, dynamic caustics, and high-speed photography to analyze the influence of static stress. The results showed that the static stress accelerates the propagation speed of explosion cracks in the direction of larger static stress, and the propagation length is longer. Besides, based on the theory of fractal rock mechanics and fracture mechanics, Deng et al. [9] proposed a new model of energy consumption. The test results showed that the fragments produced by rock fragmentation under impact load have fractal characteristics. The larger the fractal dimension, the higher the degree of rock fragmentation. In addition, Ding et al. [10] investigated the fractal damage in the breakage zone, the fracture zone, and the crush zone. The results showed that the filling medium acts as a buffer, attenuates the blast energy transfer, and inhibits the formation and development of the fracture zone. Furthermore, in order to 
explore the broken fractal characteristics of the surrounding rock of underground mine tunnels under the action of blasting load, Wang et al. [11] selected the pomegranate biotite schist as the test object and carried out a one-dimensional SHPB impact test. Analyze from the angles of shape and energy consumption density of crushing. Comparative analysis obtains a reasonable range of strain rate and a reasonable range of crushing energy density.

In the use of fractal theory combined with other aspects, Sun et al. [12] used fractal theory to calculate the correlation between stress and acoustic emission data synchronization. The results showed that the fractal characteristics of stress and acoustic emission coupling characteristics become more obvious with the increase of the correlation dimension. Liu et al. [13] evaluated the acoustic emission signal of coal fracture under uniaxial compression, combined with fractal theory to analyze the frequency spectrum, energy, and fractal characteristics of acoustic emission waveforms under different stress levels. Yang et al. [14] proposed a new method for predicting the risk of rock burst based on the analysis of the fractal dimension of the spatial distribution. It is found that the fractal dimension of the acoustic emission spatial distribution of the coal sample is significantly reduced, which verifies that the acoustic emission monitoring is carried out. Kou et al. [15] analyzed the fractal dimension of the three-dimensional failure fragments under the condition of hydraulic-mechanical coupling load. The test results showed that the peak strength of the precracked rock sample under the condition of fixed confining pressure and triaxial compression increases with the increase of internal fluid pressure. In addition, as the internal fluid pressure increases, the fracture surface roughness of the microscale crack initiation area decreases. Based on the theory of fractal theory, Zhang et al. [16] studied the influence of reservoir temperature, flow rate, and fracture morphology on the thermal convection. The results showed that with the increase of rock temperature, the outlet temperature and overall heat transfer coefficient (OHTC) increase.

At present, the dynamic mechanical characteristics of various rocks have been studied, but there are few studies on the relationship between the fractal characteristics of rock fragmentation and dissipated energy after impacted. Since the failure of the specimen is mainly a process of energy accumulation and release [17], the study of the energy dissipation characteristics during the specimen failure process can explain the failure mechanism of the specimen in a macroscopic view. In addition, the fractal dimension can be used to quantitatively express the failure form of the rock in order to reflect the degree of fracture of the specimen [18]. This paper takes the dolomite marble of the surrounding rock of Dahongshan Copper Mine of Yuxi Mining Co., Ltd. as the research object. The uniaxial impact test is carried out on the dolomite marble with the split Hopkinson pressure bar. Through the test results, the dynamic mechanical characteristics, damage degree, and energy dissipation regularity of the dolomite marble under different strain rates are analyzed. Based on the analysis, the present work can provide reference significance for analyzing the damage of dolomite marble under blasting load during roadway driving.

\section{Test Preparation and Procedure}

2.1. Test Device and Principle. This experiment was carried out on a $\Phi 50 \mathrm{~mm}$ split Hopkinson pressure bar in the Laboratory of Rock Mechanics, Kunming University of Science and Technology. As shown in Figure 1, the test system is composed of nitrogen pressure device, bullet, incident bar, transmission bar, data acquisition system, and energy absorption device. The bullet length is $0.6 \mathrm{~m}$, the incident bar and transmission bar are both $2 \mathrm{~m}$, the elastic modulus of the compression bar is $210 \mathrm{GPa}$, the material is alloy steel with a density of $7.85 \mathrm{~g} / \mathrm{cm}^{3}$, and the longitudinal wave velocity is $5190 \mathrm{~m} / \mathrm{s}$. The bullet is powered by nitrogen pressurization, and a laser velocimeter is used to measure the velocity of the bar under impact. In order to eliminate the end effect as well as the tip effect of the roadway rock specimen, a layer of petroleum jelly was smeared on both ends of the rock specimen to ensure the two end surfaces of the specimen.

The basic principle of the SHPB test is based on the theory of stress wave propagation in an elastic compression bar [19]. The three-wave method is usually used to process the test data, and the strain rate $\dot{\varepsilon}_{s}$, strain $\varepsilon$, and stress $\sigma_{s}$ of the specimen can be expressed by equation (1) [20]:

$$
\begin{aligned}
\dot{\varepsilon}_{s} & =\frac{C}{L_{s}}\left[\varepsilon_{i}(t)-\varepsilon_{r}(t)-\varepsilon_{t}(t)\right], \\
\varepsilon & =\frac{C}{L_{s}} \int_{0}^{t_{0}}\left[\varepsilon_{i}(t)-\varepsilon_{r}(t)-\varepsilon_{t}(t)\right] \mathrm{d} t, \\
\sigma_{s} & =\frac{E A}{2 A_{s}}\left[\varepsilon_{i}(t)-\varepsilon_{r}(t)-\varepsilon_{t}(t)\right],
\end{aligned}
$$

where $A_{s}, A$ is the cross-sectional area of test specimen and the compression bar $\left(\mathrm{m}^{2}\right) ; C$ is the elastic longitudinal wave velocity of the compression bar $(\mathrm{m} / \mathrm{s}) ; E$ is the modulus of elasticity of the compression bar (GPa); $L_{s}$ is the length of test specimen $(\mathrm{m}) ; \varepsilon_{i}, \varepsilon_{t}$ and $\varepsilon_{r}$ are the strains of the incident, transmitted, and reflected waves at a certain moment $t$, respectively; and $t$ is the propagation time of the stress wave in the bar (s).

The incident energy $W_{I}$, the reflected energy $W_{R}$, and the transmitted energy $W_{T}$ of the compression bar are calculated during the whole crushing process of the rock as follows [21]:

$$
\left\{\begin{array}{l}
W_{I}(t)=A E C \int_{0}^{t} \varepsilon_{I}^{2}(t) \mathrm{d} t \\
W_{R}(t)=A E C \int \varepsilon_{R}^{2}(t) \mathrm{d} t, \\
W_{T}(t)=A E C \int \varepsilon_{T}^{2}(t) \mathrm{d} t .
\end{array}\right.
$$

Neglecting the energy loss of stress waves during propagation process, the absorbed energy of rock is shown in equation (3), 


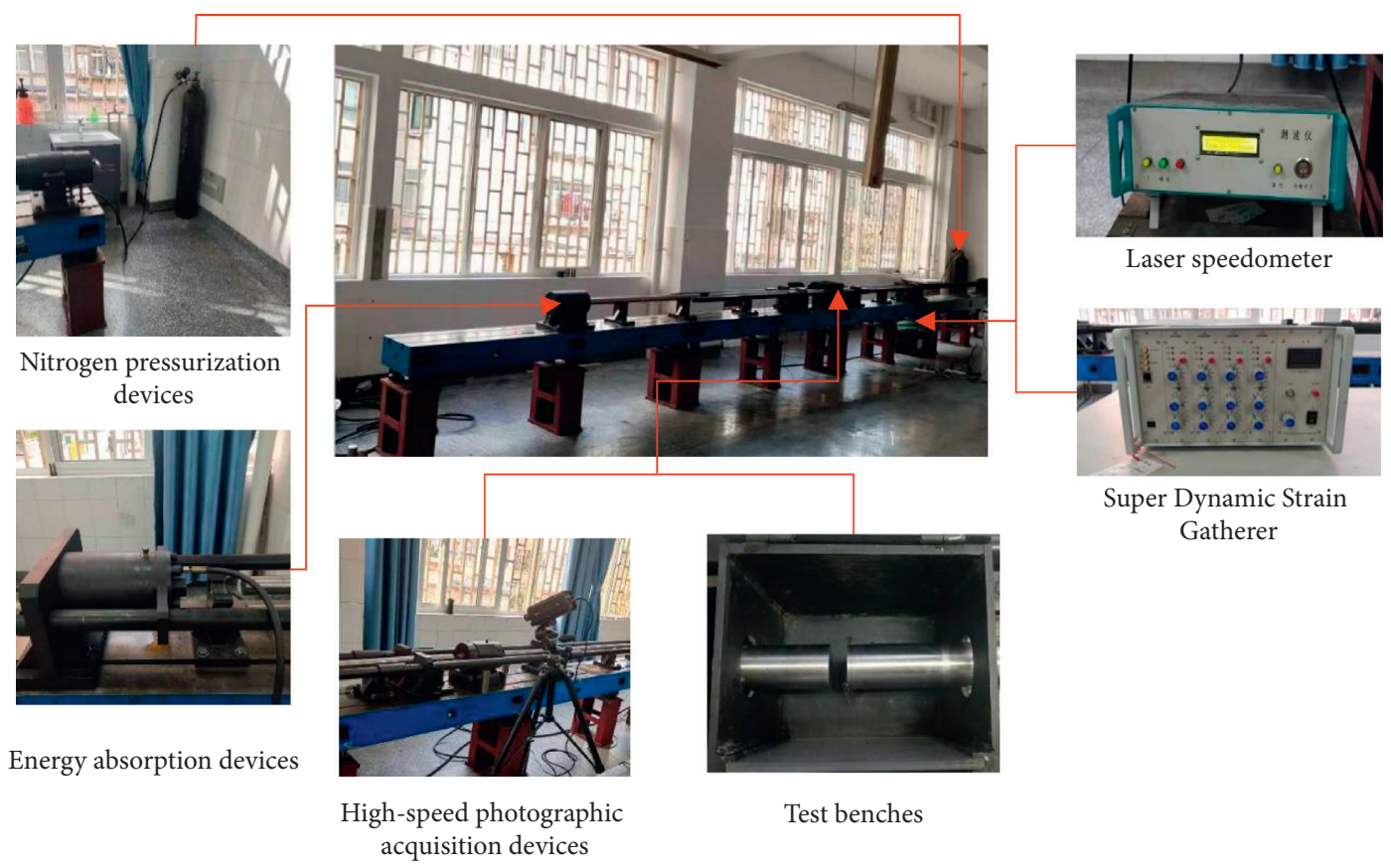

Figure 1: SHPB impact test system.

$$
W_{s}=W_{I}-\left(W_{R}+W_{T}\right) \text {. }
$$

According to the characterization method of the absorption energy per unit volume of the specimen in rock dynamics analysis, the specific energy absorption value $\omega_{c p}$ is introduced to characterize the absorption energy per unit volume of dolomite marble, and the influence of the volume factor on test results is further reduced. As shown in equation (4),

$$
\omega_{c p}=\frac{W_{s}}{V}
$$

where $W_{s}$ is the absorbed energy of specimen $(\mathrm{J})$ and $V$ is the volume of specimen $\left(\mathrm{cm}^{3}\right)$.

Meanwhile, in order to study the energy dissipation regularity of dolomite marble, $\omega_{d}$ is defined as the energy dissipation per unit mass of rock absorbed by crushing, as shown in equation (5).

$$
\omega_{d}=\frac{W_{s}}{\mathrm{M}_{s}}
$$

where $\omega_{d}$ is the crushing energy consumption per unit mass of specimen $(\mathrm{J} / \mathrm{g}) ; W_{s}$ is the absorbed energy of specimen $(\mathrm{J})$; and $M_{s}$ is the mass of specimen $(\mathrm{g})$.

2.2. Test Preparation. The specimens were taken from Yuxi Mining's Dahongshan Copper Mine. The marble was taken from a large block in the same area, in order to ensure the integrity and uniformity of rock specimens. According to the requirements of rock mechanics test, the nonparallelism of the two ends of specimen during processing should be less than $0.02 \mathrm{~mm}$. The central axis of the specimen needs to be perpendicular to the two end surfaces, and its axial deviation should be less than $\pm 0.25^{\circ}$ [22]. In order to eliminate the end effect and inertia effect of rock, the specimens were machined into cylinders with a size of $50 \mathrm{~mm} \times 50 \mathrm{~mm}$. The basic physical parameters of the specimens measured before the test are shown in Table 1 , and $D-1 \# \sim D-15 \#$ are dolomite marble specimens, as shown in Figure 2.

Before test, the specimens were prepunched to determine the optimal impact pressure. Five impact pressures of $0.40 \mathrm{MPa}, 0.45 \mathrm{MPa}, 0.50 \mathrm{MPa}, 0.55 \mathrm{MPa}$, and $0.6 \mathrm{MPa}$ were determined based on the damage pattern of the test specimen after the test. Conduct 3 sets of parallel tests for each impact air pressure, respectively, to eliminate test errors.

\section{Test Results and Analysis}

3.1. Analysis of Breakage Patterns. The damage pattern of dolomite marble was obtained by using separate tests under different impact air pressures as shown in Figure 3. At strain rates of 44.31 to $54.90 \mathrm{~s}^{-1}$, the rock breaks in a splitting pattern, which represents tensile damage [23]. At strain rates of 60.72 to $86.05 \mathrm{~s}^{-1}$, the fragmentation degree of the specimen increases with increasing strain rate, and the fragmentation size gradually decreases with the increase of the strain rate. To analyze this phenomenon, the stress wave propagates first to the specimen surface and then to the entire specimen, making the effective stress distribution uniform [24, 25]. At the same time, internal microdefects are activated and a small amount of cracks appear. As the stress continues to increase, the specimen continues to develop cracks in initial crack defect state, and cracks appear at the direction parallel to the compressive stress and gradually run through the ends of specimen, finally forming the axial splitting tensile damage. In the case of relatively complex stresses, the number of microcracks in the specimen 
TABLE 1: Average value of physical parameters of test specimen.

\begin{tabular}{lcccccccc}
\hline Specimen & $\begin{array}{c}\text { Length } \\
(\mathrm{mm})\end{array}$ & $\begin{array}{c}\text { Diameter } \\
(\mathrm{mm})\end{array}$ & $\begin{array}{c}\text { Aspect } \\
\text { ratio }\end{array}$ & $\begin{array}{c}\text { Quality } \\
(\mathrm{g})\end{array}$ & $\begin{array}{c}\text { Density } \\
\left(\mathrm{kg} \cdot \mathrm{m}^{-3}\right)\end{array}$ & $\begin{array}{c}\text { Modulus of elasticity } \\
(\mathrm{GPa})\end{array}$ & $\begin{array}{c}\text { Poisson's } \\
\text { ratio }\end{array}$ & $\begin{array}{c}\text { Compressive } \\
\text { strength }(\mathrm{MPa})\end{array}$ \\
\hline $\begin{array}{l}\text { Dolomite } \\
\text { marble }\end{array}$ & 49.53 & 48.50 & 1.02 & 270.23 & 2953.19 & 78.71 & 0.32 & 70.95 \\
\hline
\end{tabular}

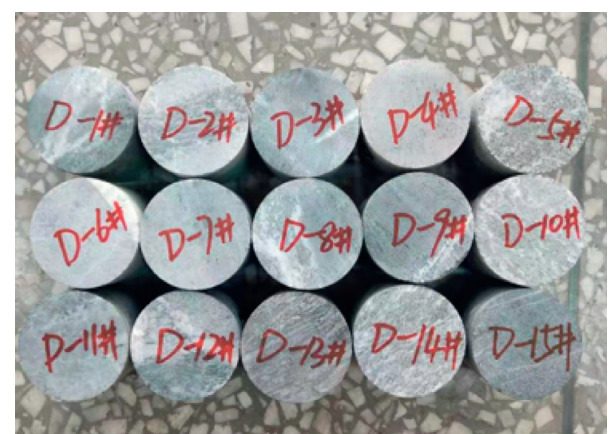

FIgURE 2: Dolomite marble.

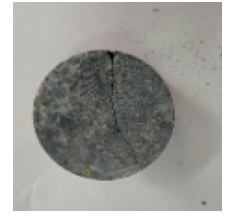

$v=10.27 \mathrm{~m} / \mathrm{s}$ $\dot{\varepsilon}=44.31 \mathrm{~s}^{-1}$
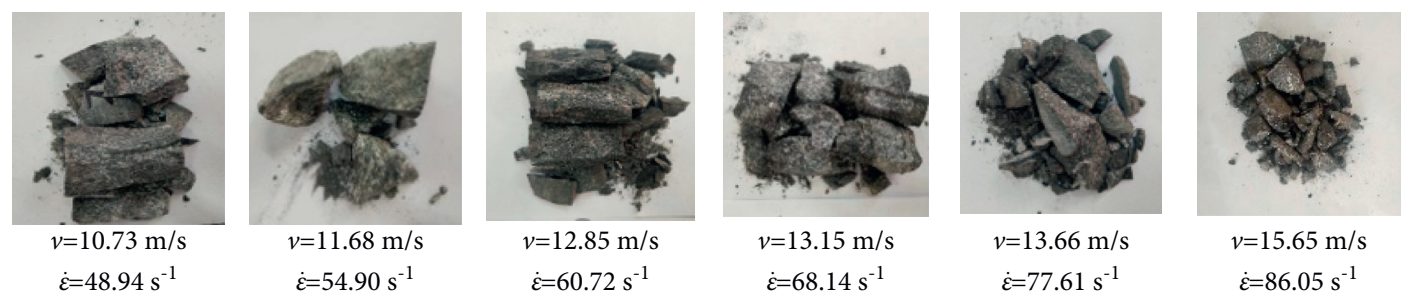

Figure 3: Failure modes of dolomite marble under different impact velocities. increases and the interaction forces between the apparent cracks grow. At the meanwhile, a certain amount of strain energy is accumulated in the specimen during the impact process. After the incident stress wave completely penetrates the specimen, the strain energy stored in the specimen starts to release and continuously promote crack penetration, thus forming the damage pattern above.

3.2. Dynamic Strength Characteristic Analysis. The characteristic parameters of rock fragmentation are shown in Table 2. The peak strain is the strain value corresponding to the peak stress in the stress-strain curve.

The relationship curves between the dynamic compressive strength of rock with the specific energy absorption value, the energy consumption per unit mass of fracture, and the strain rate are shown in Figures 4 and 5. From Figure 4, it can be seen that the dynamic compressive strength of dolomite marble presents a significant strain rate effect [26]. For example, when the strain rate increases from about $44.31 \mathrm{~s}^{-1}$ to $86.05 \mathrm{~s}^{-1}$, the dynamic compressive strength of rock increases from $163.38 \mathrm{MPa}$ to $212.6 \mathrm{MPa}$, and it has a power function relationship with the strain rate. Figure 5 shows that as the dynamic compressive strength of dolomite marble increases, the energy absorbed per unit volume and the energy consumption per unit mass of the rock gradually increase accordingly. After linear fitting results, it can be obtained that the dynamic compressive strength of the dolomite marble specimen shows significant linear relationships with the energy absorbed per unit volume and the energy consumption per unit mass. As shown in equation (6), the general formula of the regression curves is as follows:

$$
\left\{\begin{array}{l}
y_{1}=A_{1}+B_{1} \cdot \exp \left(C_{1} \cdot x\right) \\
y_{2}=A_{2}+B_{2} \cdot \exp \left(C_{2} \cdot x\right)
\end{array}\right.
$$

where $y_{1}$ is the absorbed energy per unit volume of the rock specimen, $\mathrm{J} / \mathrm{cm}^{3} ; A_{1}, B_{1}, C_{1}, A_{2}, B_{2}$, and $C_{2}$ are fitting coefficients; $y_{2}$ is the crushing energy consumption per unit mass of the rock specimen, $\mathrm{J} / \mathrm{g}$; and $x$ is the dynamic compressive strength of the rock specimen, MPa.

The dynamic compressive strength of rock changes significantly under the action of different strain rates, which is called the strain rate effect. This is the mechanical response characteristics caused by the change of one-dimensional stress state of brittle materials such as rocks. As the strain rate increases, the internal cracks of the rock develop; thus, a lot of external energy is needed for the propagation and penetration of these cracks. However, as the time of the impact loading process is extremely short, the energy accumulation is insufficient. Thus, the external energy can only be offset by increasing its own stress, and at the same time, the absorption energy per unit volume and the energy consumption per unit mass of the rock specimen are 
TABLE 2: Rock fragmentation characteristic parameters under different strain rates.

\begin{tabular}{|c|c|c|c|c|c|c|c|c|c|}
\hline $\begin{array}{c}\text { Serial } \\
\text { number }\end{array}$ & $\begin{array}{c}\text { Impact } \\
\text { pressure/ } \\
\mathrm{MPa}\end{array}$ & $\begin{array}{c}\text { Impact } \\
\text { velocity/ } \\
\left(\mathrm{m} \cdot \mathrm{s}^{-1}\right)\end{array}$ & $\begin{array}{l}\text { Strain } \\
\text { rate/ } \\
\left(\mathrm{s}^{-1}\right)\end{array}$ & $\begin{array}{c}\text { Dynamic } \\
\text { compressive } \\
\text { strength/MPa }\end{array}$ & $\begin{array}{l}\text { Peak } \\
\text { strain }\end{array}$ & $\begin{array}{l}\text { Incident } \\
\text { energy/J }\end{array}$ & $\begin{array}{c}\text { Absorbed } \\
\text { energy/J }\end{array}$ & $\begin{array}{l}\text { Specific energy } \\
\text { absorption/ } \\
\left(\mathrm{J} \cdot \mathrm{cm}^{-3}\right)\end{array}$ & $\begin{array}{l}\text { Absorbed } \\
\text { energy per unit } \\
\text { mass }\left(\mathrm{J} \cdot \mathrm{g}^{-1}\right)\end{array}$ \\
\hline D-2\# & 0.40 & 10.27 & 44.31 & 163.38 & 0.0084 & 153.08 & 51.28 & 0.56 & 0.19 \\
\hline D-4\# & 0.43 & 10.73 & 48.94 & 165.63 & 0.0075 & 168.68 & 54.11 & 0.59 & 0.20 \\
\hline D-5\# & 0.45 & 11.68 & 54.90 & 175.77 & 0.0089 & 190.36 & 58.77 & 0.65 & 0.21 \\
\hline D-7\# & 0.50 & 12.85 & 60.72 & 190.03 & 0.0096 & 235.74 & 68.41 & 0.75 & 0.25 \\
\hline D-9\# & 0.58 & 13.15 & 68.14 & 194.47 & 0.0090 & 246.88 & 70.22 & 0.77 & 0.25 \\
\hline D-10\# & 0.55 & 13.66 & 77.61 & 201.39 & 0.0102 & 279.48 & 76.36 & 0.84 & 0.28 \\
\hline D-12\# & 0.60 & 15.65 & 86.05 & 212.68 & 0.0113 & 349.95 & 88.96 & 0.98 & 0.32 \\
\hline
\end{tabular}

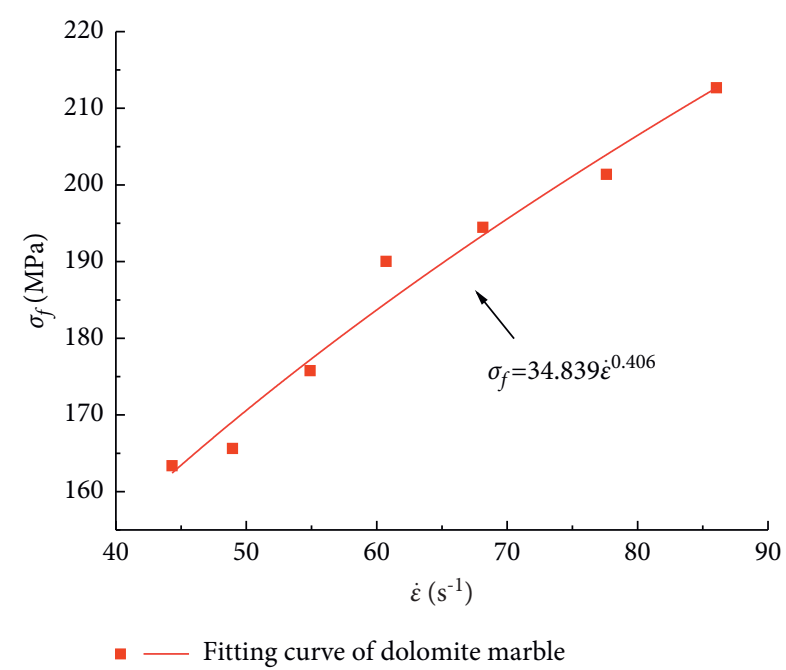

FIGURE 4: Relationship between the dynamic compressive strength and strain rate of dolomite marble.

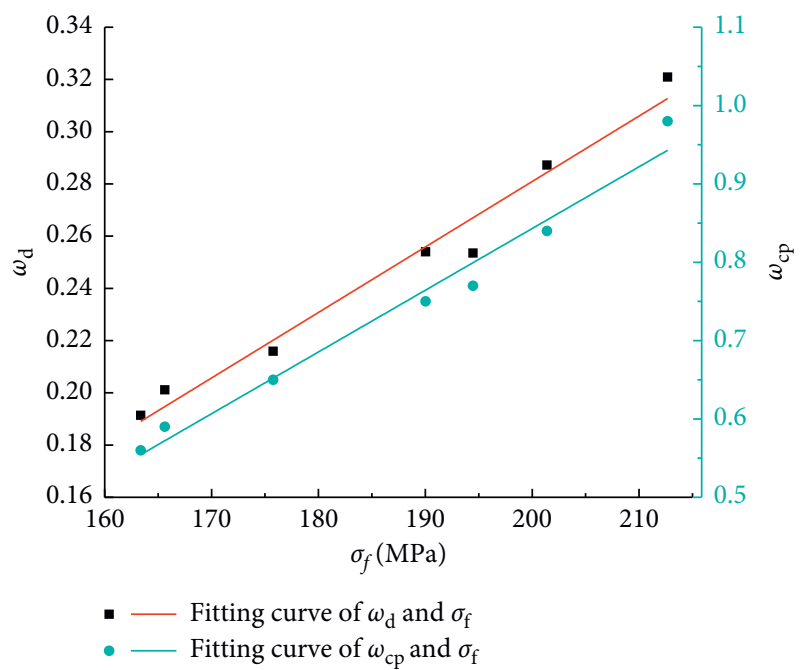

FIGURE 5: Relationship between the dynamic compressive strength of dolomite marble with $\omega_{d}$ and $\omega_{c p}$.

increased. Therefore, for actual working conditions such as roadway blasting and mechanical dynamic loading, the dynamic mechanical strength of the surrounding rock should be fully considered when the roadway is excavated or supported.

\subsection{Fractal Characteristics of Rocks}

3.3.1. Fragment Screening and Calculation of Fractal Dimension. In order to quantitatively describe the degree of fragmentation of the specimen, it can be expressed intuitively by the fragmentation distribution of the fragments after the rock specimen is broken, which can reflect the regularity of the failure degree of the rock specimen with the increasing strain rate. Use a standard sieve of $0-25 \mathrm{~mm}$ size to screen the impacted rock specimens, weigh the mass of the remaining fragments on the sieve (Table 3), and then convert it to the percentage of rock fragments of different sieve sizes. The fragmentation distribution curve of dolomite marble is shown in Figure 6.

As can be seen from Figure 6, the percentage of the dolomite marble fragments with the size larger than $25 \mathrm{~mm}$ after impact damage under conventional uniaxial impact loading is above $35.19 \%$ in all cases. As the strain rate increases from $44.31 \mathrm{~s}^{-1}$ to $86.05 \mathrm{~s}^{-1}$, the proportion of the fragments larger than $25 \mathrm{~mm}$ decreases from $66.71 \%$ to $35.19 \%$, with relatively flat changes for the distribution of fragments equal to or smaller than $20 \mathrm{~mm}$ in size.

In addition to the particle size distribution, the fractal dimension is also an important indicator of the fractal characteristics of rock, which increases with the degree of fragmentation of the specimen [27].

$$
Y=\left(\frac{r}{r_{m}}\right)^{b}
$$

where $b$ is the corresponding regression coefficient, and on the basis of the mass-frequency relationship, the crushing bulk distribution equation of rock specimen can be obtained as follows:

$$
\begin{aligned}
Y & =\frac{M_{r}}{M_{t}}, \\
& =\left(\frac{r}{r_{m}}\right)^{3-D},
\end{aligned}
$$

where $M r$ is the mass of rock fragments with a particle size less than $r$; Mt is the total mass of rock fragments; and $r_{m}$ is the maximum particle size. The following equation can be obtained by taking logarithm on both sides of equation (8) at the same time: 
TABLE 3: Impact test sieve sizes and corresponding weighing masses.

\begin{tabular}{lccccccccccc}
\hline \multirow{2}{*}{ Strain rate $\left(\mathrm{s}^{-1}\right)$} & & \multicolumn{9}{c}{ Sieving diameter $(\mathrm{mm})$} & \multicolumn{3}{c}{ Total $(\mathrm{g})$} \\
& 0 & 0.3 & 0.5 & 1 & 2.5 & 5 & 10 & 15 & 20 & 25 \\
\hline 44.31 & 0.22 & 0.35 & 1.54 & 0.83 & 1.23 & 5.34 & 10.33 & 28.71 & 40.89 & 179.81 & 269.25 \\
48.94 & 0.42 & 1.01 & 1.21 & 2.51 & 2.48 & 9.13 & 8.69 & 31.76 & 43.91 & 168.04 & 269.16 \\
54.90 & 0.72 & 1.76 & 1.72 & 3.89 & 3.52 & 8.04 & 20.21 & 40.97 & 40.2 & 142.76 & 263.79 \\
60.72 & 2.48 & 3.65 & 3.31 & 10.93 & 3.26 & 14.32 & 33.52 & 50.28 & 27.97 & 116.82 & 266.54 \\
68.14 & 1.59 & 5.34 & 10.2 & 4.57 & 13.47 & 20.43 & 47.55 & 14.28 & 28.87 & 119.44 & 265.77 \\
77.61 & 7.72 & 3.76 & 2.72 & 17.89 & 8.24 & 38.04 & 38.47 & 15.43 & 17.89 & 112.76 & 262.92 \\
86.05 & 5.45 & 4.37 & 9.85 & 22.42 & 19.9 & 29.45 & 27.45 & 33.42 & 22.36 & 94.85 & 269.52 \\
\hline
\end{tabular}

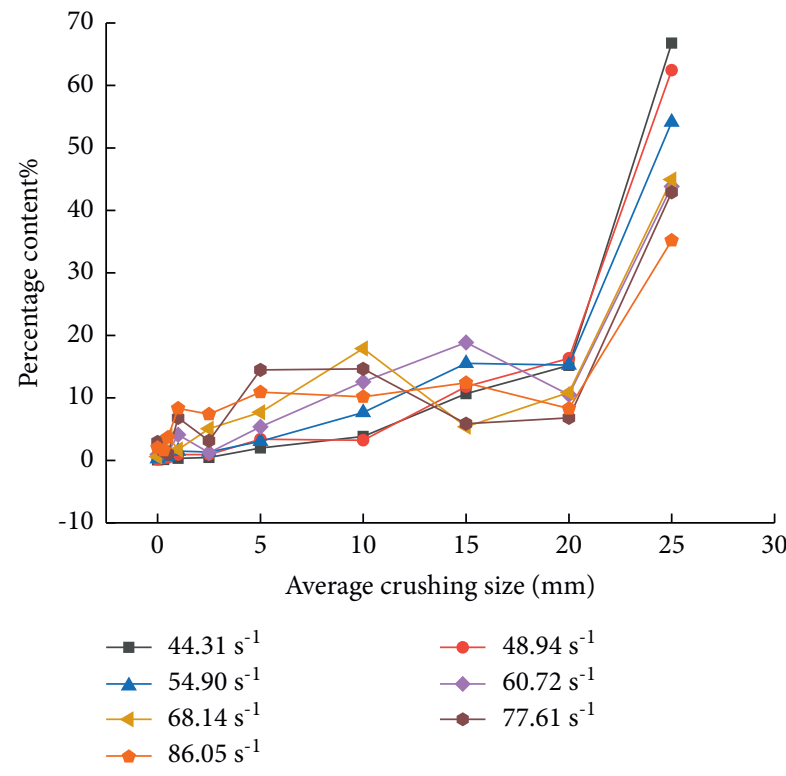

FIGURE 6: Fragmentation distribution of dolomite marble under different strain rates.

$$
\begin{aligned}
\ln Y & =\ln \left[\frac{M_{r}}{M_{t}}\right], \\
& =(3-D) \ln \left(\frac{r}{r_{m}}\right) .
\end{aligned}
$$

Therefore, the slope of the line fitted through the coordinate system of $\ln \left[M_{r} / M_{t}\right]-\ln r$ is the fractal dimension $D$.

The $\ln \left[M_{r} / M_{t}\right]-\ln x$ curves for the distribution of dolomite marble fragments are shown in Figure 7.

As can be seen from Figure 7, the percentage of cumulative mass under the sieve for crushed bulk of dolomite barite is linearly correlated with the sieve hole size in a double logarithmic coordinate system. And the slope of its particle size characteristic curve decreases with increasing strain rate, indicating a gradual increase in mass at the fines end of the crushed dolomite barite and a deeper degree of crushing. The average fragmentation size and fractal dimension $D$ of the dolomite marble fragments are shown in Table 4 . The correlation coefficients $R^{2}$ are all at high levels from the data listed in the table, indicating that the distribution of rock fragmentation mass under impact loading is consistent with the fractal pattern.

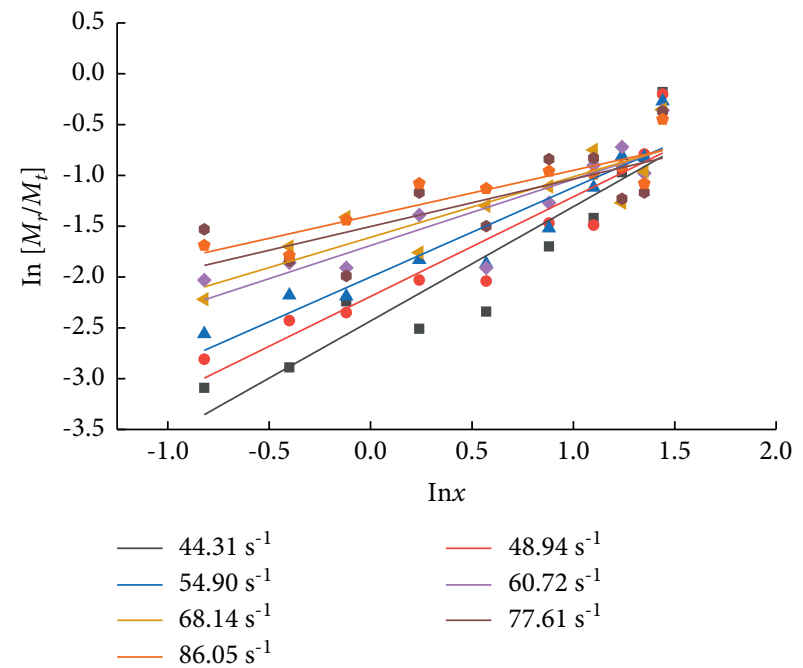

FiguRE 7: Grain size characteristic curve of dolomite marble.

3.3.2. Relationship between Fractal Dimension with Strain Rate and Average Fragmentation. It can be seen from Figure 7 that the linear fitting degree of the double logarithm function image is as high as, indicating that the self-similarity of the fragmentation distribution after rock fragmentation is high, or the fractal characteristics are significant. The reason is that the aggregation of small internal cracks leads to the macroscopic destruction of rock, which is in turn formed by multiplication of smaller cracks, and this self-similarity eventually leads to a self-similarity in the distribution of size. Thus, a quantitative description of rock fragmentation can be expressed in terms of fractal dimension. The fractal dimension $D$ is therefore related to the strain rate and the average fragment size, respectively (see Figures 8 and 9). The average fragment size is expressed as a block size with a cumulative percentage under a screen of $50 \%$. The formula is shown in equation (10).

$$
d_{s}=\frac{\sum r_{i} d_{i}}{\sum r_{i}}
$$

where $d_{s}$ is the average size of the crushed rock mass at different screen diameters; $r_{i}$ is the screen diameter; and $d_{i}$ is the percentage of rock mass.

The following analysis yields the law of block size distribution and the law of change in the degree of fragmentation of rocks under different dynamic loads. It can be seen from Figures 8 and 9 that the fractal dimension has a linear 
TABLE 4: Fragmentation statistics of dolomite marble under impact loading.

\begin{tabular}{|c|c|c|c|c|c|c|c|}
\hline Specimen no. & D-2\# & D-4\# & D-5\# & D-7\# & D-9\# & D-10\# & D-12\# \\
\hline Average crushing size $/ \mathrm{mm}$ & 24.30 & 23.62 & 22.30 & 19.82 & 18.81 & 17.52 & 16.27 \\
\hline Fractal dimension & 1.88 & 2.02 & 2.12 & 2.35 & 2.40 & 2.54 & 2.57 \\
\hline Correlation coefficient $R^{2}$ & 0.85 & 0.87 & 0.88 & 0.75 & 0.75 & 0.81 & 0.77 \\
\hline
\end{tabular}

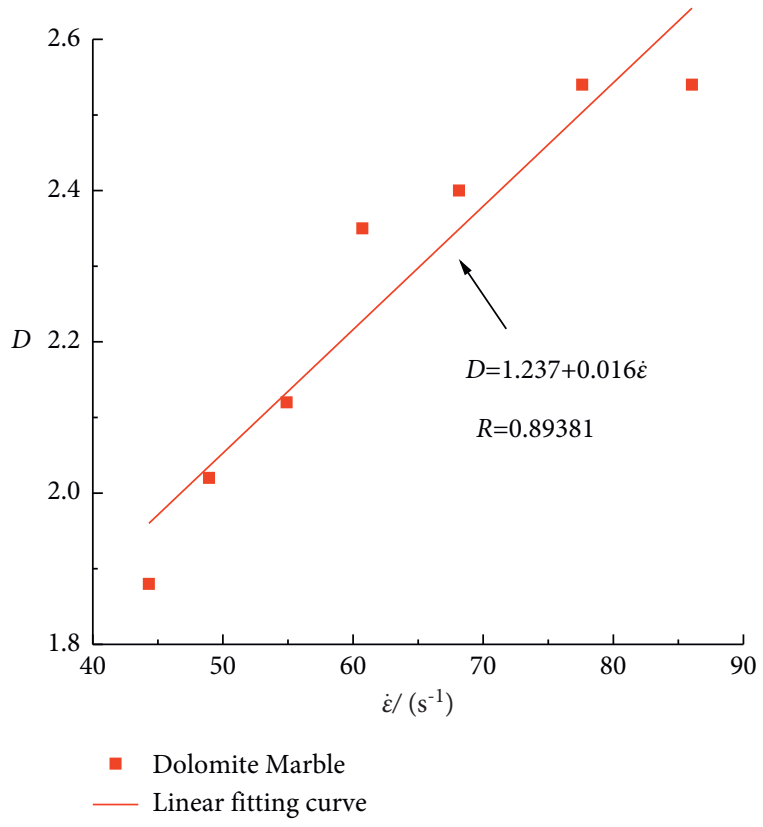

Figure 8: Relationship between the fractal dimension and the strain rate.

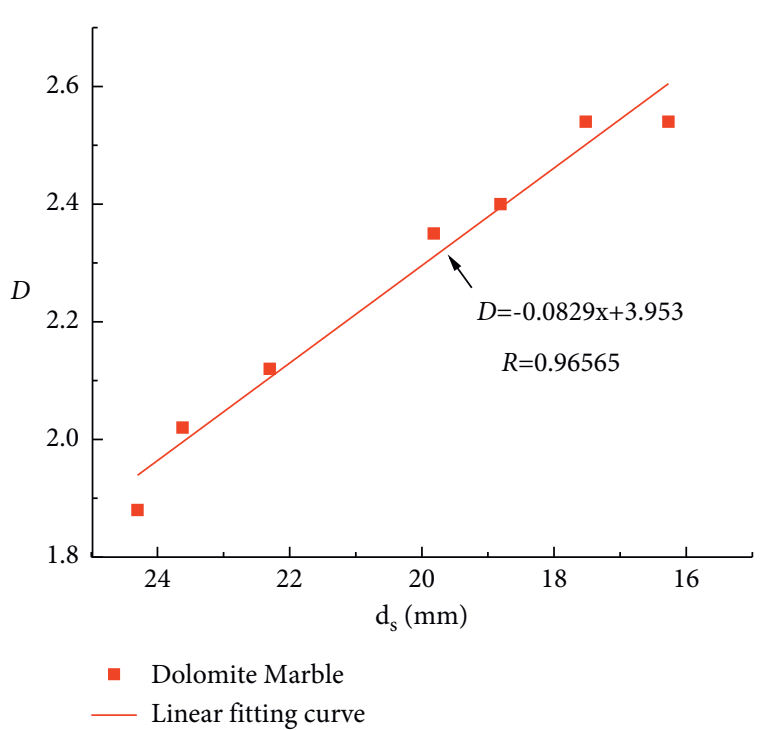

Figure 9: Relationship between the fractal dimension and the average fragmentation size.

relationship with strain rate and average fragmentation size, and the correlation between the two is strong. In the experiment, the strain rate of dolomite marble increases from $48.94 \mathrm{~s}^{-1}$ to $86.05 \mathrm{~s}^{-1}$, the fractal dimension $D$ increases from 2.02 to 2.54 , and the average fragmentation size decreases from $23.62 \mathrm{~mm}$ to $16.27 \mathrm{~mm}$. It shows that the fragmentation distribution of dolomite marble has self-similarity characteristic, and the fractal characteristics are significant.

3.4. Regularity of Energy Dissipation. According to the regularity of thermodynamics, rock failure is actually a process of energy absorption, transformation, and release [28-31]. This is because the energy dissipation characteristics of the rock during damage are closely related to its internal damage level. As a direct result of the external energy acting on the rock causing internal damage to the rock, each stage of the cracking process requires external energy to replenish, multiply, sprout, expand, and penetrate, and the whole process is an energy dissipation process. Therefore, using the concept of energy dissipation can reflect the whole process of rock deformation and damage more reasonably. At the same time, the law of energy dissipation also plays an important role in rock mining [32-35] and fracture simulation [36, 37].

3.4.1. Specific Energy Absorption Value, Absorbed Energy, and Incident Energy. The specific energy absorption value is an effective index to determine the energy absorbed by rock under impact load, which indicates the intensity of energy absorbed per unit volume in impact compression test. Figure 10 shows the relationship between the specific energy absorption values and the absorbed energy with incident energy for the dolomite marble specimens. It can be seen from this figure that the specific energy absorption values and absorbed energy of the rock specimens increase with the increase of incident energy and have strong linear relationships, with the regression coefficient of the fitted curves larger than 0.9.

3.4.2. Crushing Size and Energy Consumption. According to the screening results of rock fragmentation, the relationship between average fragmentation and specific energy absorption value and the relationship between fractal dimension and specific energy absorption value can be obtained. The average fragment size of rock specimens under different impact loads is 16.27-24.30, and the fractal dimension is 1.88-2.57. As shown in Figure 11, the mass fractal dimension of dolomite marble specimens increases with increasing specific energy absorption value and shows a linear relationship, while the average fragmentation size decreases with the increasing specific energy absorption value and shows an exponential function.

The greater the specific energy absorption value, i.e., the energy consumption density, the greater the degree of rock fragmentation. This is because the more the energy consumed per unit volume of the rock specimen during the impact compression test, the more energy is used to deform and break the rock and the faster the microcracking breed development, resulting in more fracture surfaces and smaller 


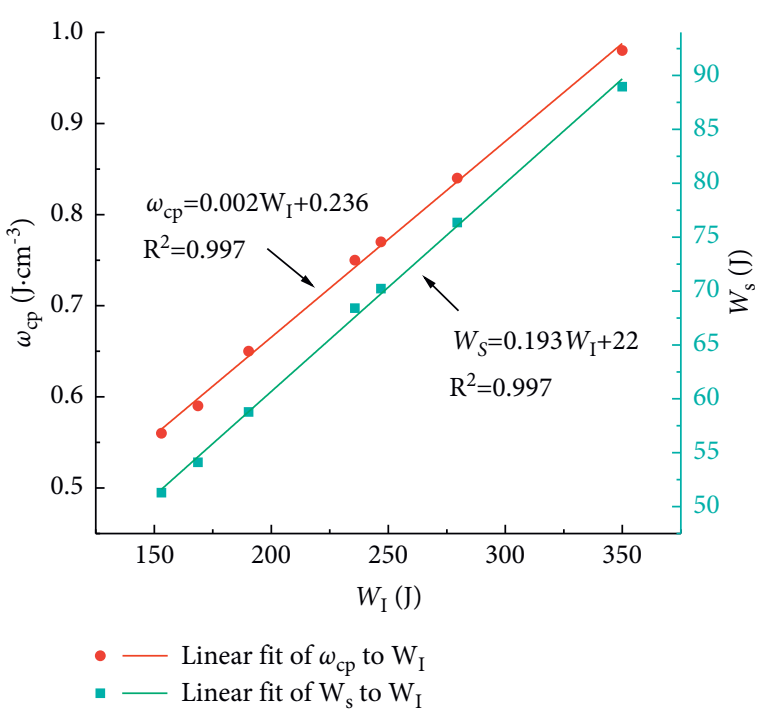

FIGURE 10: Relationship between specific energy absorption values with absorbed energy and incident energy.

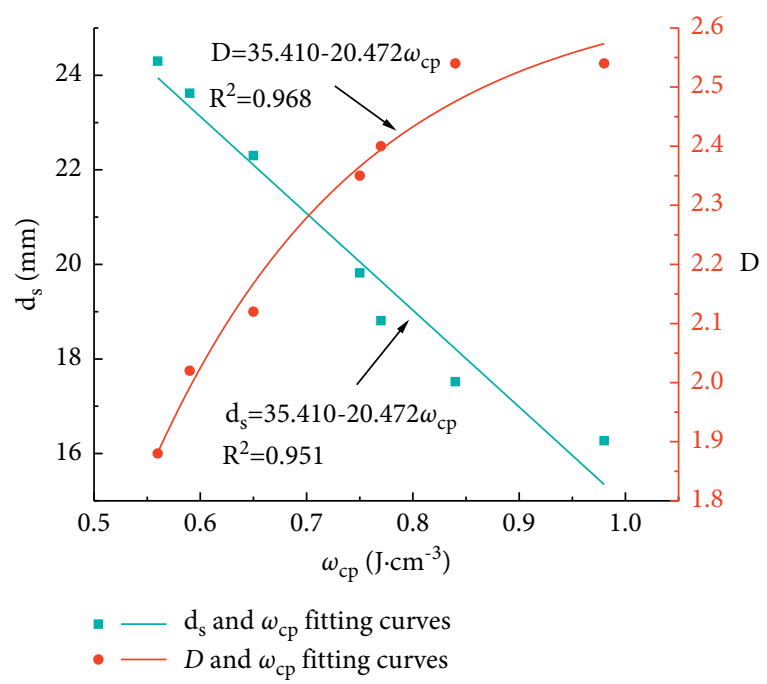

FIGURE 11: Relationship between average fragment size and specific energy absorption value.

scale fragments. The average fragment size can therefore be used to quantify the degree of rock fragmentation.

3.4.3. Degree of Fragmentation and Energy Dissipation in Relation to Strain Rate. In order to investigate the variation of specific energy absorption value and fragmentation degree of dolomite marble at different strain rates, the relationship between specific energy absorption value, average fragmentation size, incident energy, and strain rate at different strain rates is given in Figure 12. The analysis shows that the specific energy absorption value of the rock specimen increases with increasing strain rate which is in linear correlation, with a fitted curve data correlation coefficient of 0.967. The mean crushing bulk increases with increasing

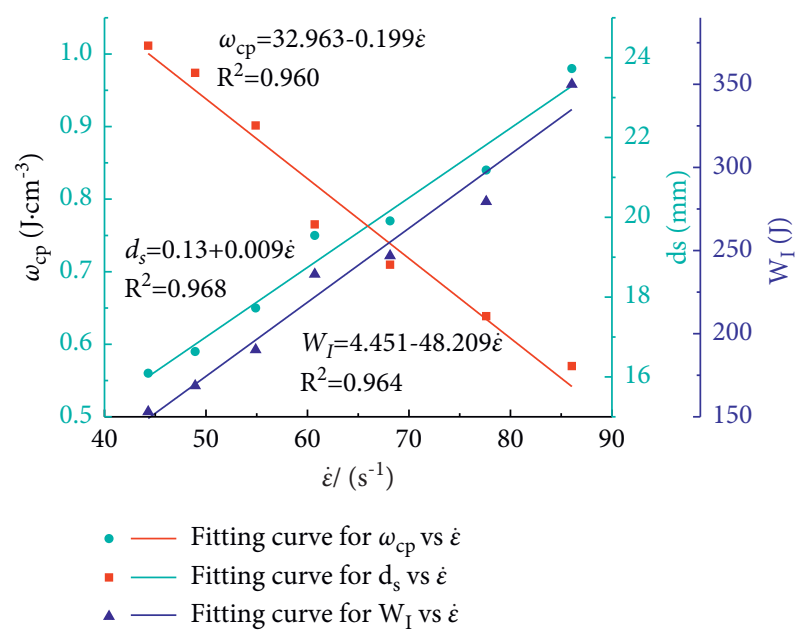

FIGURE 12: Curves of specific energy absorption, average fragmentation, and incident energy at different strain rates.

strain rate which is also linearly correlated, with a fitted curve data correlation coefficient of 0.968 . The incident energy increases with increasing strain rate in a roughly linear relationship, with a fitted curve data correlation coefficient of 0.964. As the strain rate increases and new cracks created in the rock specimen, more energy is absorbed by the specimen. The higher the specific energy absorption value, the higher the incident energy, but the average fragmentation size is reduced. Therefore, increasing the strain rate can significantly increase the degree of rock fragmentation.

Rock failure can be seen as a process of continuous energy transformation, where the underlying cause of deformation and damage is the dissipation of energy. Therefore, it is necessary to use energy dissipation to characterize the fracture degree of rock. The variation of specific energy absorption value, average fragmentation size, and incident energy with strain rate is shown in Figure 12. As can be seen from this figure, when the strain rate is low, the rock is less damaged, with more large blocks and fewer small blocks. As the strain rate increases, the fragmentation of rock deepens, with the amount of large masses decreasing and the amount of small masses gradually increasing. The specific energy absorption value increases with increasing strain rate, which indicates that the more the energy absorbed by the rock, the smaller the rock fragmentation and the deeper the fragmentation.

\section{Discussion}

In summary, an increase in strain rate allows the effective crushing bulk of the rock to gradually migrate toward the fine grain end, enhancing the crushing effect $[38,39]$. However, the increased crushing effect means that the crushing energy consumption density (specific energy absorption value) increases. Therefore, a reasonable range of strain rate and crushing energy consumption density is of great practical importance to enhance rock crushing and reduce energy consumption. The slope of the particle size characteristic curve in Figure 7 is characterized as the distribution of rock fragmentation size, also known as the bulk distribution factor 


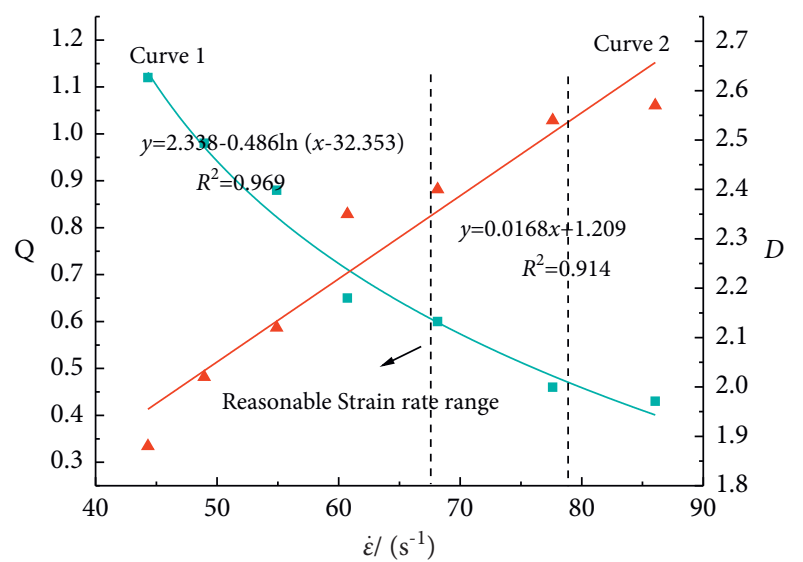

- Bulk distribution factor

- Fractal dimension

FIGURE 13: The relationship diagram for determining the reasonable strain rate range.

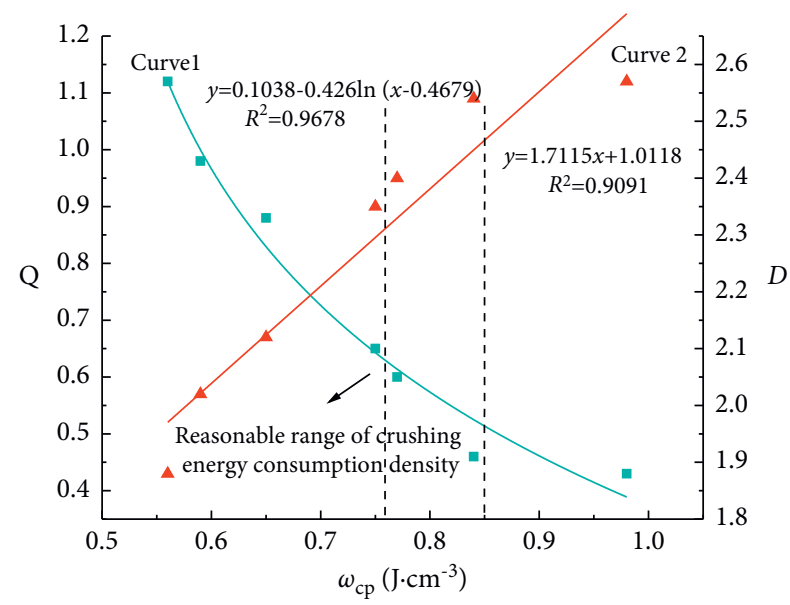

- Bulk distribution factor

$\Delta$ Fractal dimension

FIGURE 14: The relationship diagram for determining the reasonable range of crushing energy consumption density.

Q. Figure 13 shows the bulk distribution factor $Q$ and fractal dimension $D$ as a function of strain rate, and Figure 14 shows the bulk distribution factor $Q$ and fractal dimension $D$ as a function of crushing energy dissipation density.

From the fragment size distribution coefficient curve in Figure 13, it can be seen that the slope of the curve changes faster and the decline rate increases when $\dot{\varepsilon}$ approaches $48.94 \mathrm{~s}^{-1}$. Therefore, in order to achieve a better crushing effect the $\dot{\varepsilon}$ interval can be initially chosen to be 48.94 to $77.61 \mathrm{~s}^{-1}$, and from the fractal dimension curve the $\dot{\varepsilon}$ interval is $68.14-86.05 \mathrm{~s}^{-1}$. Similarly, the two curves in Figure 14 give the crushing energy density ranges of $0.65-0.84 \mathrm{~J} / \mathrm{cm}^{3}$ and $0.75-0.98 \mathrm{~J} / \mathrm{cm}^{3}$, respectively.

According to the relationship between strain rate and crushing energy density in Table 2 , the reasonable strain rate range to achieve rock crushing can be treated as the intersection of the above sets, which should be $68.14-77.61 \mathrm{~s}^{-1}$, and the reasonable crushing energy density range should be $0.65-0.98 \mathrm{~J} / \mathrm{cm}^{3}$ (the dashed line range in Figures 13 and 14).

\section{Conclusions}

In this paper, a representative dolomite marble was selected to carry out SHPB rock dynamic mechanical tests, and a series of test results were obtained, including rock fragmentation characteristics, strength index, and energy parameters under different strain rates. The final research investigated the relationship between the kinetic parameters and the fractal dimension, and provides a reference basis for further research on the dynamic mechanical properties of high ground stress rocks in triaxial impact tests. The following conclusions were mainly obtained:

(1) There is a significant strain rate effect on the dynamic compressive strength of dolomite marble. The dynamic compressive strength increases with increasing strain rate and satisfies a multiplicative power relationship. The absorbed energy per unit volume and the crushing energy per unit mass of rock both increase linearly with increasing dynamic compressive strength.

(2) The fractal dimension $D$ can quantify the crushing characteristics and energy dissipation of rock. The distribution of fractal size of dolomite marble under impact loading satisfies the fractal regularity, and the fractal dimension $D$ increases with increasing strain rate. The fractal dimension $D$ of dolomite marble at strain rates ranging from 44.31 to $86.05 \mathrm{~s}^{-1}$ is $1.88-2.57$, and the average fragmentation size is $16.27-24.30 \mathrm{~mm}$.

(3) The whole deformation and damage process of the dolomite marble can be reasonably explained by the concept of energy dissipation. The greater the specific energy absorption value of a rock under impact loading, the smaller the average fragmentation size of the rock and the greater the fractal dimension, indicating a larger intense fragmentation of the rock.

(4) The reasonable strain rate range for the dolomite marble to both improve the crushing effectiveness and reduce the crushing energy consumption is $68.14-77.61 \mathrm{~s}^{-1}$, and the reasonable range of crushing energy consumption density is $0.65-0.98 \mathrm{~J} / \mathrm{cm}^{3}$.

\section{Data Availability}

The data used to support the findings of this study are included in the article.

\section{Disclosure}

Zehu Zhao is the co-first author.

\section{Conflicts of Interest}

The authors declare that they have no conflicts of interest. 


\section{Authors' Contributions}

Conceptualization, methodology, validation, data curation, visualization, and writing original draft preparation were performed by Z. T. and X. L.; experimental guidance and data analysis were performed by J. W.; theoretical analysis was carried out by Z. Z.; formal analysis writing, reviewing, and editing were conceived by all authors. All authors have read and agreed to the published version of the manuscript.

\section{Acknowledgments}

This study was financially supported by the National Natural Science Foundation of China (No. 52064025), and its support is gratefully appreciated.

\section{References}

[1] L. Huang and Y. Chen, "Rock dynamics in China: past, present and future," Chinese Journal of Rock Mechanics and Engineering, vol. 11, pp. 1881-1886, 2003.

[2] K. Xia, S. Wang, Y. Xu, R. Chen, and B. Wu, "Advances in experimental studies for deep rock dynamics," Chinese Journal of Rock Mechanics and Engineering, vol. 40, no. 3, pp. 448-475, 2021.

[3] K. Xia, Y. Xu, and R. Chen, "Dynamic tests of rocks subjected to simulated deep underground environments," Hazard Control in Tunnelling and Underground Engineering, vol. 1, no. 1, pp. 58-75, 2019.

[4] D. Asprone, E. Cadoni, A. Prota, and G. Manfredi, "Dynamic behavior of a Mediterranean natural stone under tensile loading," International Journal of Rock Mechanics and Mining Sciences, vol. 46, no. 3, pp. 514-520, 2009.

[5] R. Guo, H. Ren, L. Zhang et al., "Research progress of largediameter split Hopkinson bar experimental technique," Acta Armamentarii, vol. 40, no. 7, pp. 1518-1536, 2019.

[6] Z. Wang and Z. Lu, "Application of SHPB in experimental teaching of rock dynamics," Research and Exploration in Laboratory, vol. 33, no. 1, pp. 214-216+258, 2014.

[7] Q. Ma, D. Ma, P. Yuan, and Z. Yao, "Energy absorption characteristics of frozen soil based on SHPB test," Advances in Materials Science and Engineering, vol. 2018, pp. 1-9, Article ID 5378173, 2018.

[8] C. Ding, R. Yang, Z. Lei, M. Wang, Y. Zhao, and H. Lin, "Fractal damage and crack propagation in decoupled charge blasting," Soil Dynamics and Earthquake Engineering, vol. 141, Article ID 106503, 2021.

[9] Y. Deng, M. Chen, Y. Jin, and D. Zou, "Theoretical analysis and experimental research on the energy dissipation of rock crushing based on fractal theory," Journal of Natural Gas Science and Engineering, vol. 33, pp. 231-239, 2016.

[10] C. Ding, R. Yang, and L. Yang, "Experimental results of blastinduced cracking fractal characteristics and propagation behavior in deep rock mass," International Journal of Rock Mechanics and Mining Sciences, vol. 142, Article ID 104772, 2021.

[11] J. Wang, T. Zuo, X. Li, Z. Tao, and J. Ma, "Study on the fractal characteristics of the pomegranate biotite schist under impact loading," Geofluids, vol. 2021, Article ID 1570160, 8 pages, 2021.

[12] H. Sun, X. L. Liu, and J. B. Zhu, "Correlational fractal characterisation of stress and acoustic emission during coal and rock failure under multilevel dynamic loading,"
International Journal of Rock Mechanics and Mining Sciences, vol. 117, pp. 1-10, 2019.

[13] S. Liu, X. Li, Z. Li, P. Chen, X. Yang, and Y. Liu, "Energy distribution and fractal characterization of acoustic emission (AE) during coal deformation and fracturing," Measurement, vol. 136, pp. 122-131, 2019.

[14] X. Yang, T. Ren, and X. He, "Experimental study of coal burst risk prediction using fractal dimension analysis of AE spatial distribution," Journal of Applied Geophysics, vol. 177, Article ID 104025, 2020.

[15] M. Kou, X. Liu, S. Tang, and Y. Wang, “3-D X-ray computed tomography on failure characteristics of rock-like materials under coupled hydro-mechanical loading," Theoretical and Applied Fracture Mechanics, vol. 104, Article ID 102396, 2019.

[16] P. Zhang, Y. Zhang, and Y. Huang, "Experimental study of convective heat transfer characteristics of fractures with different morphologies based on fractal theory," Case Studies in Thermal Engineering, vol. 28, Article ID 101499, 2021.

[17] J. Liu, L. Ma, N. Zhang, and Y. Wang, "Research progress on energy evolution in the process of rock deformation and failure," Chinese Journal of Underground Space and Engineering, vol. 17, no. 3, pp. 975-986, 2021.

[18] R. Wu, H. Li, X. Li, C. Yu, X. Xia, and L. Liu, "Broken energy dissipation and fragmentation characteristics of layered rock under impact loading," Journal of China Coal Society, vol. 45, no. 3, pp. 1053-1060, 2020.

[19] L. Chen, X. Zhang, and G. Liu, "Analysis of dynamic mechanical properties of sprayed fiber-reinforced concrete based on the energy conversion principle," Construction and Building Materials, vol. 254, Article ID 119167, 2020.

[20] C. Liu, D. Wang, Z. Wang, B. Ke, P. Li, and S. Yu, "Dynamic splitting tensile test of granite under freeze-thaw weathering," Soil Dynamics and Earthquake Engineering, vol. 140, Article ID 106411, 2021.

[21] Z. Han, D. Li, T. Zhou, Q. Zhu, and P. G. Ranjith, "Experimental study of stress wave propagation and energy characteristics across rock specimens containing cemented mortar joint with various thicknesses," International Journal of Rock Mechanics and Mining Sciences, vol. 131, Article ID 104352, 2020.

[22] S. Zhang, L. Wang, L. Lu, S. Wang, and D. Feng, "Weakening effects of occurrence structural plane on mechanical properties of silty mudstone," Chinese Journal of Geotechnical Engineering, vol. 42, no. 11, pp. 2015-2023, 2020.

[23] M. Zhang, W. Wang, Q. Wang, and S. Zhang, "Study on dynamic failure process and strain-damage law of sandstone based on SHPB test," Explosion and Shock Waves, vol. 41, pp. 1-16, 2021.

[24] Y. Liu, C. He, H. Fu, S. Wang, Y. Lei, and Y. Peng, "Study on tensile mechanical properties and energy consumption law of saturated slate under impact loads," Chinese Journal of Rock Mechanics and Engineering, vol. 39, no. 11, pp. 2226-2233, 2020.

[25] Q. Ma, Q. Su, D. Ma, and P. Yuan, "SHPB experimental study on dynamic characteristics and failure behaviors of sandstone containing weakly filled joints with various angles in deep roadways," Chinese Journal of Rock Mechanics and Engineering, vol. 39, no. 6, pp. 1104-1116, 2020.

[26] Y. Yang, N. Zhang, and J. Wang, "A study on the dynamic strength deterioration mechanism of frozen red sandstone at low temperatures," Minerals, vol. 11, no. 12, p. 1300, 2021.

[27] L. Xie, Q. Li, and S. Xu, "Experimental study on fractal characteristics of steam free reactive powder concrete under 
impact load," Engineering Mechanics, vol. 38, no. 03, pp. 169-180, 2021.

[28] Y. Zhang, B. Li, J. Xu, Z. Gao, S. Chen, and B. Wang, "Study on triaxial compression damage evolution characteristics of coal based on energy dissipation," Chinese Journal of Rock Mechanics and Engineering, vol. 40, no. 08, pp. 1614-1627, 2021.

[29] H. P. Xie, Y. Ju, L. Y. Li, and R. D. Peng, "Energy mechanism of deformation and failure of rock masses," Chinese Journal of Rock Mechanics and Engineering, vol. 27, no. 9, pp. 1729-1740, 2008.

[30] Y. Hou, S. Yin, Y. Cao, and C. Dai, "Research on damage and energy dissipation characteristics of cemented backfill under different loading rates," Journal of Hunan University. Natural Sciences, vol. 47, no. 8, pp. 108-117, 2020.

[31] K. Man, Z. Song, and X. Liu, "Dynamic tensile test of granite and its tensile sensitivity," Advances in Civil Engineering, vol. 2020, no. 9, Article ID 8837865, 2020.

[32] S. Wang, Y. Tang, X. Li, and K. Du, "Analyses and predictions of rock cuttabilities under different confining stresses and rock properties based on rock indentation tests by conical pick," Transactions of Nonferrous Metals Society of China, vol. 31, no. 6, pp. 1766-1783, 2021.

[33] S. Wang, L. Sun, X. Li et al., "Experimental investigation of cuttability improvement for hard rock fragmentation using conical cutter," International Journal of Geomechanics, vol. 21, no. 2, p. 06020039, 2021.

[34] S. Wang, X. Li, J. Yao et al., "Experimental investigation of rock breakage by a conical pick and its application to nonexplosive mechanized mining in deep hard rock," International Journal of Rock Mechanics and Mining Sciences, vol. 122, Article ID 104063, 2019.

[35] S. Wang, Y. Tang, and S. Wang, "Influence of brittleness and confining stress on rock cuttability based on rock indentation tests," Journal of Central South University, vol. 28, no. 9, pp. 2786-2800, 2021.

[36] B. Gong, S. Wang, S.W. Sloan, D. Sheng, and C. Tang, "Modelling rock failure with a novel continuous to discontinuous method," Rock Mechanics and Rock Engineering, vol. 52, no. 6, 2019.

[37] B. Gong, C. Tang, S. Wang, H. Bai, and Y. Li, "Simulation of the nonlinear mechanical behaviors of jointed rock masses based on the improved discontinuous deformation and displacement method," International Journal of Rock Mechanics and Mining Sciences, vol. 122, Article ID 104076, 2019.

[38] Z. Zhang, Q. Qian, H. Wang, Y. Huang, J. Wang, and H. Liu, "Study on the dynamic mechanical properties of metamorphic limestone under impact loading," Lithosphere, vol. 4, Article ID 8403502, 2021.

[39] X. Li, Z. Tao, J. Wang, T. Zuo, J. Ma, and Q. Li, "Strain rate effect on mechanical properties of cemented backfill under dynamic and static combined loading," Shock and Vibration, vol. 2021, Article ID 2196838, 11 pages, 2021. 